\title{
Telbivudine Treatment during Late Pregnancy Prevents Mother-to-Child Transmission of Hepatitis B Virus: A Retrospective Study
}

\author{
Mengzhi Cai $\left(\mathbb{D},{ }^{1}\right.$ Yanli Hao $\mathbb{D},{ }^{1}$ Jianxin Zhong $\left(\mathbb{D},{ }^{2}\right.$ Wei Yao $\mathbb{D}{ }^{2}$ \\ Xia Cao ${ }^{1}{ }^{3}$ Guifang Gu ${ }^{3},{ }^{3}$ and Gang Qin ${ }^{1}{ }^{1}$ \\ ${ }^{1}$ Center for Liver Diseases, Nantong Third People's Hospital, Nantong University, Nantong 226006, China \\ ${ }^{2}$ Department of Obstetrics and Gynaecology, Affiliated Hospital of Nantong University, Nantong 226001, China \\ ${ }^{3}$ Department of Obstetrics and Gynaecology, Nantong Third People's Hospital, Nantong University, Nantong 226006, China
}

Correspondence should be addressed to Guifang Gu; 1873448762@qq.com and Gang Qin; tonygqin@ntu.edu.cn

Received 5 December 2018; Revised 1 April 2019; Accepted 24 June 2019; Published 9 July 2019

Academic Editor: Michele Molinari

Copyright (c) 2019 Mengzhi Cai et al. This is an open access article distributed under the Creative Commons Attribution License, which permits unrestricted use, distribution, and reproduction in any medium, provided the original work is properly cited.

\begin{abstract}
Purpose. To investigate the efficacy of telbivudine (LdT) in blocking mother-to-child transmission (MTCT) of hepatitis B virus (HBV) during late pregnancy. Methods. A total of 651 pregnant women aged 18-40 in Nantong Third People's Hospital and Hospital affiliated to Nantong University with positive hepatitis B surface antigen (HBsAg) and HBV DNA were enrolled between January 2011 and December 2015. Patients with HBV DNA $\geq 10^{6}$ copies/mL $(\mathrm{n}=251)$ received LdT during late pregnancy according to the patients' will, while 136 high viral patients with HBV DNA $\geq 10^{6}$ copies $/ \mathrm{mL}$ who did not take LdT therapy and 268 low viral patients with HBV DNA $<10^{6}$ copies $/ \mathrm{mL}$ served as the controls. Results. At 7 months and 1 year postpartum, the basal HBV DNA serum level of treated patients declined significantly $(P<0.001)$, while no obvious decline was observed in the untreated high viraemic controls $(P<0.05)$ and untreated low viraemic controls $(P<0.05)$. Only 1 infant $(0.4 \%)$ in LdT group was HBsAg positive at 7 months, while $14(5.2 \%)$ were in the untreated low viraemic controls $(P<0.001)$ and $15(11.0 \%)$ were in untreated high viraemic controls $(P<0.001)$. Conclusion. For pregnant women with HBV DNA $\geq 10^{6}$ copies $/ \mathrm{mL}$, the use of LdT during late pregnancy could effectively reduce the MTCT rate of HBV.
\end{abstract}

\section{Introduction}

Hepatitis B virus (HBV) infection has always been a threat to public health. More than 240 million people are affected by chronic HBV all over the world [1]. About 650 thousand people died from HBV-related liver cirrhosis and hepatic cellular carcinoma (HCC) every year [2]. About $2 \%$ to $10 \%$ of the patients with chronic hepatitis $\mathrm{B}(\mathrm{CHB})$ may progress to liver cirrhosis every year. For noncirrhotic patients with HBV infection, the annual incidence of HCC is $0.5 \%$ to $1 \%$. For cirrhotic patients with HBV infection, the annual incidence of HCC is $3 \%$ to $6 \%$ [3]. The proportion of liver cirrhosis and HCC caused by HBV infection is $30 \%$ and $45 \%$ worldwide [4], while in China the proportion is $60 \%$ and $80 \%[5,6]$. In countries with a high prevalence of HBV, mother-to-child transmission (MTCT) still accounts for most cases with HBV infections $[7,8]$. Most of perinatal infections may progress to $\mathrm{CHB}$ and then evolve to HBV-related liver cirrhosis and cancer [9-12]. MTCT, or perinatal transmission, or vertical transmission refers to detectable HBV DNA and/or hepatitis B surface antigen ( $\mathrm{HBsAg}$ ) in peripheral serum samples of infants at 7 months $[13,14]$. The application of HBV vaccine $(0,1$, and 6 months) and hepatitis B immune globulin (HBIG) for infants could decrease the risk of MTCT from $90 \%$ to 5\%$10 \%$ [15-18], but MTCT still occurs in infants born to women with high HBV viral load $[10,15,19]$, and the risk of MTCT is particularly high for women with HBV viral load $\left(\geq 10^{6}\right.$ of DNA $/ \mathrm{mL}$ ) [20]. Now, the application of antiviral drugs during late pregnancy to block MTCT is recommended in many countries, including China $[9,21]$. Telbivudine (LdT) and Tenofovir disoproxil fumarate (TDF), the only category $\mathrm{B}$ (no risk in animal studies, but unknown in human) drugs 
according to the Food and Drug Administration (FDA), remain the first choice for antiviral therapy in China [22].

We conducted this retrospective cohort study based on a total of 651 pregnant women aged 18-40 with positive $\mathrm{HBsAg}$ and HBV DNA from Nantong Third Peoples Hospital and Affiliated Hospital of Nantong University between January 2011 and December 2015 to study the efficacy of LdT in blocking MTCT of HBV during late pregnancy. Clinical data of the pregnant women were all available during pregnancy and within 1 year postpartum; clinical data of the infants were available at birth and 7 months postpartum.

\section{Methods}

2.1. Study Design. A retrospective review of the treatment and follow-up of patients aged 18-40 with positive HBsAg and HBV DNA and their respective infants were undertaken in Nantong Third People's Hospital and Affiliated Hospital of Nantong University from January 2011 to December 2015. All participants were identified using codes from the International Classification of Disease, 10th edition (ICD$10)$. The codes used to identify viral hepatitis complicating pregnancy, childbirth, and the puerperium were O95.482 [23, 24]. According to the above method, 651 pregnant women satisfied the inclusion criteria and were enrolled. Among participants of this study, 247 were from Nantong Third People's Hospital and 404 were from Hospital affiliated to Nantong University.

All subjects in this study fulfilled the following criteria: (i) 18-40 years old; (ii) HBsAg positive; (iii) HBV DNA positive; (iv) clinical data of the pregnant women all available during pregnancy and 1 year postpartum and clinical data of the infants available at birth and at 7 months postpartum. The exclusion criteria were as follows: (i) antiviral treatment within 1 year; (ii) coinfection with hepatitis A, C, D, and E or human immunodeficiency virus (HIV).

The protocol of this retrospective study without any intervention was reviewed and approved by both institutional review boards (IRBs). All data were processed anonymously. Informed consent was waived by the same IRBs.

2.2. Data Collection. Data regarding perinatal HBV infection were collected and submitted by dedicated personnel from the two participating hospitals: All subjects were classified into three groups. 264 patients with $\mathrm{HBV}$ DNA $<10^{6}$ copies/mL served as group A. 136 patients with high viral load (HBV DNA $\geq 10^{6}$ copies/mL) who did not receive $\mathrm{LdT}$ therapy represented group B. 251 patients with high viral load (HBV DNA $\geq 10^{6}$ copies $/ \mathrm{mL}$ ) who received LdT therapy were classified in group $\mathrm{C}$.

Patients in group A took the prenatal examination regularly. Patients in group B were prescribed anti-inflammatory and hepatoprotective drugs and did not take antiviral drugs. Patients in group C received LdT (Novartis, Swiss) $600 \mathrm{mg}$ orally daily at 28-32 weeks of gestation [24-26]. Patients with elevated ALT level received neo-minophagen C or magnesium isoglycyrrhizinate, and polyene phosphatidylcholine. All the infants received $100 \mathrm{IU}$ hepatitis B immune globulin
(HBIG) and $10 \mu \mathrm{g}$ of HBV vaccine intramuscularly within 12 hours after birth, and then $10 \mathrm{ug}$ additional vaccines at 1 and 6 months of age [27]. 85.7\% patients in group C continued to take LdT or switched to other antiviral drugs at 1 year postpartum.

The HBV serum markers (HBV-M) were detected by enzyme-linked immunosorbent assay kit (Abbott Labs, Chicago, USA). HBV DNA was detected by the real-time quantitative polymerase chain reaction (qPCR) amplification kit (detectable baseline of HBV DNA was $10^{3}$ copies $/ \mathrm{mL}$, Kehua Biological Company, Shanghai, China).

2.3. Efficacy Assessment. The primary efficacy measure was the MTCT rate. Secondary efficacy measure was the reduction of serum HBV DNA levels (decrease $\geq 2 \log 10$ copies $/ \mathrm{mL}$ from baseline), rate of undetectable $\mathrm{HBV}$ DNA (HBV $\mathrm{DNA}<10^{3}$ copies $/ \mathrm{mL}$ ), the normalization rate of ALT, and other parameters such as adverse events, gestation age, incidence of postpartum hemorrhage, rate of meconium staining of the amniotic fluid, premature rupture of membrane, and mode of delivery. Data regarding the infant assessment were Apgar score (5 minute), the birth weight, the rate of low birth weight infant, the incidence of preterm birth, and signs of fetal distress.

2.4. Statistical Methods. Continuous variables were summarized as mean \pm standard deviation and dependent $t$ test was used for comparisons of two groups. Categorical variables were summarized as number or percentage and chi-square test was used for in-between group comparisons. A $P$-value of $<0.05$ was considered significant. Logistic regression was used to study the potential risk factors of infants with HBV infection. All analyses were conducted with Stata Software version 13.1 (StataCrop, USA).

\section{Results}

3.1. Baseline Characteristics of Pregnant Women and Newborn Infants. In total, 714 pregnant women were enrolled, and 651 were qualified for the final analysis. 264 low viral patients (group A) and 136 high viral patients who did not receive antiviral therapy (group B) served as controls. 251 high viral patients who received antiviral therapy at the third trimester were the treatment group (group C) (Figure 1).

There were no significant differences among the pregnant women of the three groups regarding age, primipara status, mode of delivery, premature rupture of membrane, meconium staining of the amniotic fluid (II-III degree) [28], and postpartum hemorrhage. The gestation week of the patients in group $\mathrm{A}$ was longer than that in group $\mathrm{B}$ and group $\mathrm{C}(6.7 \%$ vs. $12.5 \%, P<0.05 ; 12.5 \%$ vs. $12.4 \%, P>0.05)$. There were also no significant differences among the newborn babies Apgar scores, low birth weight, premature birth, and fetal distress (Table 1).

3.2. Efficacy of Telbivudine: Mothers. The HBV DNA level of the patients is shown in Table 2. There was a significant difference in the reduction of serum HBV DNA (decrease $\geq 2$ 


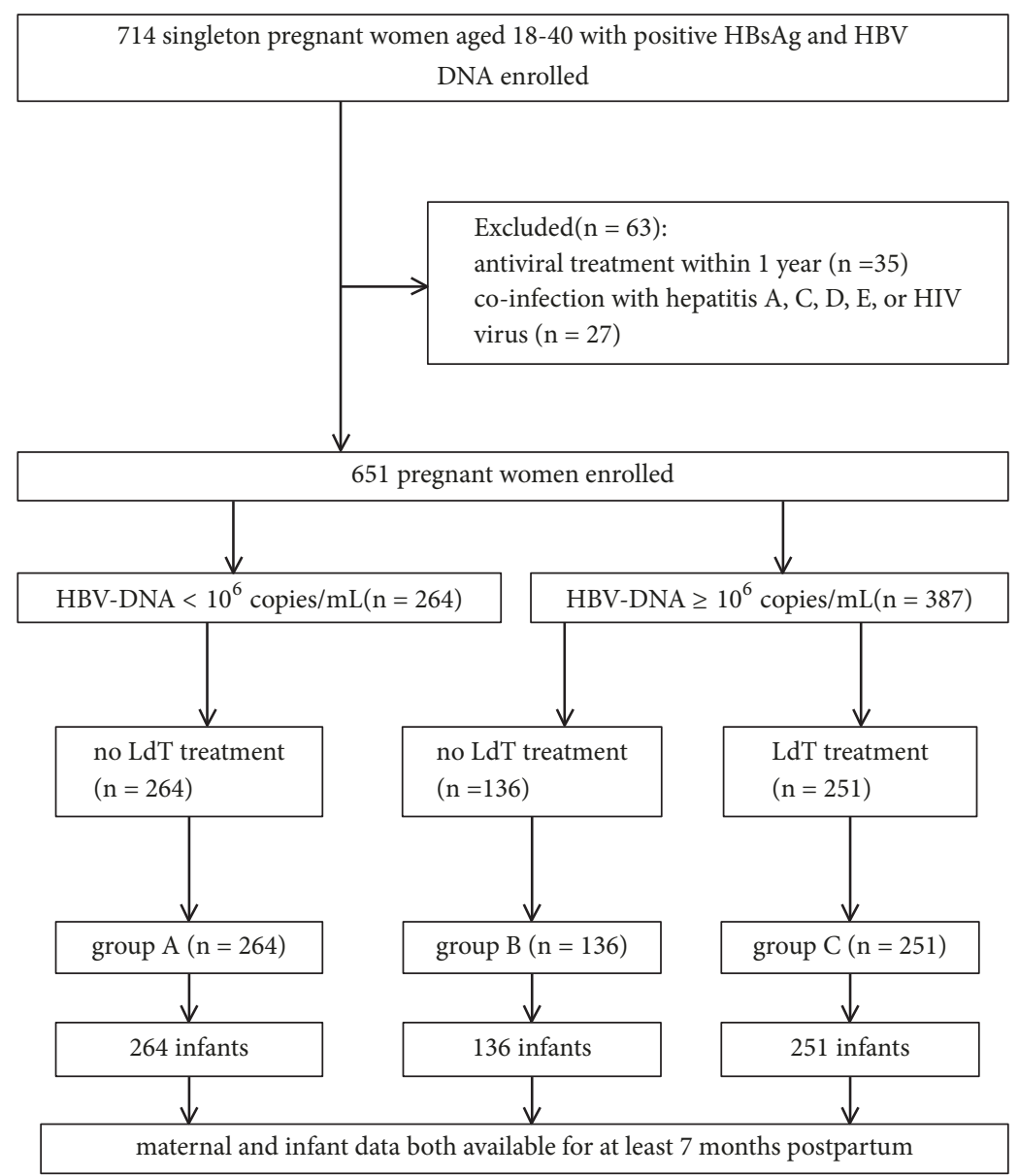

FIGURE 1: Flowchart of patients' enrollment. HBV, hepatitis B virus; HBsAg, hepatitis B surface antigen; LdT, telbivudine.

log10copies/mL from baseline). 237 (94.4\%) patients in group $\mathrm{C}$ had a significant decline of serum HBV DNA (decrease $\geq 2$ $\log 10$ copies/mL from baseline) prior to their delivery while no patients in groups $\mathrm{A}$ and $\mathrm{B}$ had a reduction of HBV DNA (94.4\% vs. $0 \%$ vs. $0 \%, P<0.001) .85 .7 \%$ patients in group $\mathrm{C}$ continued to take LdT or switched to other antiviral drugs at 1 year postpartum. The lower detection limit of $\mathrm{HBV}$ DNA was $10^{3}$ copies/mL. In group C, and $21(8.4 \%)$ patients had undetectable HBV DNA before delivery. The number increased to $132(52.6 \%)$ at 7 months postpartum and 151 $(60.2 \%)$ at 1 year postpartum, suggesting the effectiveness of telbivudine therapy (Table 2).

The ALT level of the patients in group A did not decline. The ALT of the patients in group B decreased after the use of liver-protection drugs. In group C, 134 (53.4\%) patients achieved normal ALT level before delivery. More than $80 \%$ patients in group C kept normal level of ALT at 7 months postpartum (83.7\%) and 1 year postpartum (87.3\%) (Table 3).

3.3. Efficacy of Telbivudine: Infants. 651 newborn babies were born from 651 pregnant women. Data regarding 7 months follow-up suggested that the MTCT rate in group C was $0.4 \%$ (infants with $\mathrm{HBsAg}$ positive at 7 months of age), compared with 14 (5.3\%) and 15 (11.0\%) in group A and group B mothers (11.0\% vs. $0.4 \%, P<0.001$ ) (Table 4 ).

Univariate analysis revealed that LdT treatment was associated with lower risk (odds ratio $=0.05,95 \%$ confidence interval 0.01-0.38; $P<0.001)$ and HBV DNA levels were associated with higher risk (odds ratio $=1.39,95 \%$ confidence interval 1.17-1.64) of infant HBsAg positivity at 7 months. Multivariate analysis showed that only two factors were independently associated with MTCT of HBV: high HBV DNA before delivery (OR 1.21, 95\% CI 1.02-1.44) and LdT treatment (OR 0.07, 95\% CI 0.01-0.55) (Table 5).

\section{Discussion}

Maternal viral load is the most important risk factor for MTCT of HBV. Studies have shown that patients with high viral load (HBV DNA $\geq 10^{6}$ copies/mL) are closely correlated with $\mathrm{HBV}$ infection of their infants $[5,10,20$, $29,30]$. Neonatal active-passive combination immunization cannot completely block MTCT [17, 31, 32]. NAs treatment (such as LdT and TDF) for patients with high viral load ( $\mathrm{HBV}$ DNA $\geq 10^{6}$ copies $/ \mathrm{mL}$ ) during late pregnancy can effectively block the MTCT of HBV and has been reported by several other studies [14, 33, 34]. In 


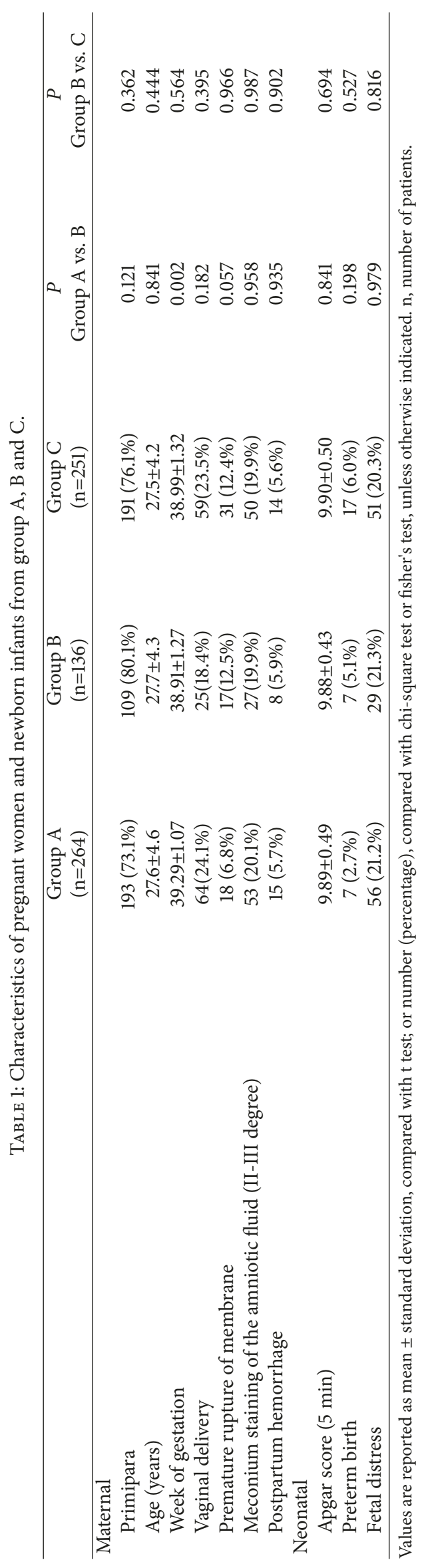




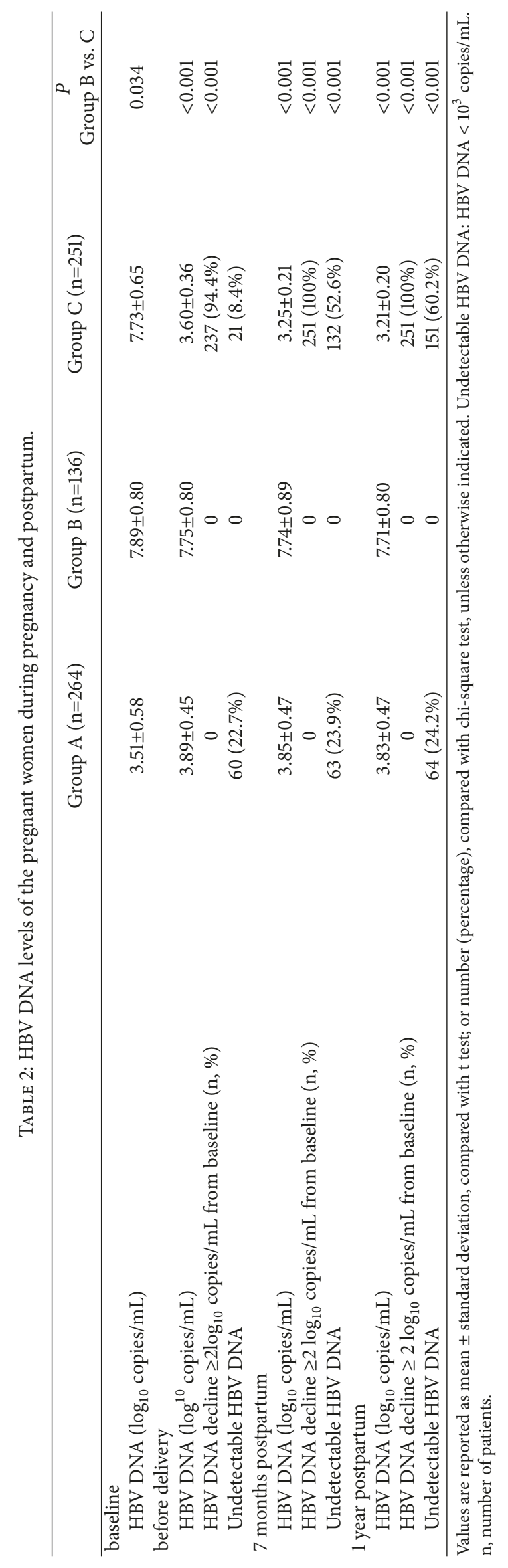


TABLE 3: ALT levels of the pregnant women during pregnancy and postpartum.

\begin{tabular}{|c|c|c|c|c|}
\hline & $\begin{array}{l}\text { Group A } \\
(n=264)\end{array}$ & $\begin{array}{c}\text { Group B } \\
(n=136)\end{array}$ & $\begin{array}{c}\text { Group C } \\
(n=251)\end{array}$ & $\begin{array}{c}P \\
\text { Group B vs. C }\end{array}$ \\
\hline Baseline (U/L) & $33.13 \pm 9.95$ & $127.49 \pm 68.23$ & $120.63 \pm 67.07$ & 0.340 \\
\hline $0-40$ & $218(82.6 \%)$ & 0 & 0 & 0.369 \\
\hline $41-80$ & $46(17.4 \%)$ & $42(30.9 \%)$ & $90(35.9 \%)$ & \\
\hline $81-200$ & 0 & $73(53.68 \%)$ & $134(53.39 \%)$ & \\
\hline $201-400$ & 0 & $21(15.44 \%)$ & $26(10.36 \%)$ & \\
\hline $401-$ & 0 & 0 & $1(0.40 \%)$ & \\
\hline Before delivery (U/L) & $32.89 \pm 9.25$ & $53.13 \pm 14.88$ & $42.00 \pm 12.01$ & $<0.001$ \\
\hline $0-40$ & $219(83.0 \%)$ & $31(22.8 \%)$ & $134(53.4 \%)$ & $<0.001$ \\
\hline $41-80$ & $45(17.0 \%)$ & $97(71.3 \%)$ & $114(45.4 \%)$ & \\
\hline $81-200$ & 0 & $8(5.9 \%)$ & $3(1.2 \%)$ & \\
\hline $201-400$ & 0 & 0 & 0 & \\
\hline $401-$ & 0 & 0 & 0 & \\
\hline 7 months postpartum (U/L) & $27.24 \pm 8.21$ & $60.18 \pm 14.12$ & $31.06 \pm 1.66$ & $<0.001$ \\
\hline $0-40$ & $241(91.3 \%)$ & $3(2.2 \%)$ & $210(83.7 \%)$ & $<0.001$ \\
\hline $41-80$ & $23(8.7 \%)$ & $116(85.3 \%)$ & $41(16.3 \%)$ & \\
\hline $81-200$ & 0 & $17(12.5 \%)$ & 0 & \\
\hline $201-400$ & 0 & 0 & 0 & \\
\hline $401-$ & 0 & 0 & 0 & \\
\hline 1 year postpartum (U/L) & $26.54 \pm 7.85$ & $58.83 \pm 1.16$ & $29.01 \pm 8.66$ & $<0.001$ \\
\hline $0-40$ & $243(92.0 \%)$ & $4(2.9 \%)$ & $219(87.3 \%)$ & $<0.001$ \\
\hline $41-80$ & $21(8.0 \%)$ & $119(87.5 \%)$ & $32(12.7 \%)$ & \\
\hline $81-200$ & 0 & $13(9.6 \%)$ & 0 & \\
\hline $201-400$ & 0 & 0 & 0 & \\
\hline $401-$ & 0 & 0 & 0 & \\
\hline
\end{tabular}

Values are reported as mean \pm standard deviation, compared with $\mathrm{t}$ test; or number (percentage), compared with chi-square test or fisher's test, unless otherwise indicated. $\mathrm{n}$, number of patients; ALT, alanine aminotransferase.

TABLE 4: HBsAg and anti-HBs status of the infants.

\begin{tabular}{lcccc}
\hline & $\begin{array}{c}\text { Group A } \\
(\mathrm{n}=264)\end{array}$ & $\begin{array}{c}\text { Group B } \\
(\mathrm{n}=136)\end{array}$ & $\begin{array}{c}\text { Group C } \\
(\mathrm{n}=251)\end{array}$ & $\begin{array}{c}P \\
\text { Group B vs. C }\end{array}$ \\
\hline $\begin{array}{l}\text { HBsAg } \\
\text { At birth }\end{array}$ & $16(6.06 \%)$ & $17(12.50 \%)$ & $15(5.98 \%)$ & 0.026 \\
7 months & $14(5.30 \%)$ & $15(11.03 \%)$ & $1(0.40 \%)$ & $<0.001$ \\
Anti-HBs & & & & \\
7 months & $232(87.88 \%)$ & $131(96.32 \%)$ & $249(99.20 \%)$ & 0.055 \\
\hline
\end{tabular}

Values are reported as number (percentage), compared with chi-square test or fisher's test. n, number of patients.

our study, we confirmed that maternal viral load was an independent risk factor for MTCT. Furthermore, we have shown LdT treatment could significantly reduce the MTCT incidence.

MTCT rate of $\mathrm{HBV}$ was $0 \%$ for pregnant women with low viral load $[17,35,36]$. On the other hand, the MTCT rate in our cohort was $5.30 \%(14 / 264)$ for infants born to mothers who were in the untreated-low group. A meta-analysis from Chen et al. [37] reported that the incidence of MTCT for mother with HBV DNA $<10^{6}$ copies/mL was $2.75 \%$ (95\% CI, 1.20-4.31), indicating that pregnant women with low viral load can still infect their babies with HBV. Whether antiviral treatment is needed for low viral patients requires further investigations.

Maternal HBeAg positivity was also reported as an independent risk factor for MTCT in several studies [3840]. A study from Chen et al. [41] reported that MTCT rate of $\mathrm{HBeAg}$ positive mothers (54/583) was significantly higher than that of $\mathrm{HBeAg}$ negative mothers (4/1773) $(9.26 \%$ vs. $0.23 \%, P<0.001$ ). In our study, the MTCT rate was $4.73 \%$ for mothers with positive HBeAg, compared with $4.3 \%$ for mothers with negative $\mathrm{HBeAg}$ (4.73\% vs. $4.3 \%$ ).

There are limited data concerning the safety of LdT treatment during late pregnancy [20,34, 42]. Recently, a 
TABLE 5: Risk factors for MTCT of HBV.

\begin{tabular}{|c|c|c|c|}
\hline & Case/exposed, \% & Univariate OR $(95 \% \mathrm{CI})$ & Adjusted OR (95\% CI) \\
\hline \multicolumn{4}{|l|}{ Age } \\
\hline$<35$ & $27 / 595,4.54 \%$ & 1 & \\
\hline$\geq 35$ & $3 / 56,5.36 \%$ & $1.19(0.35-4.06)$ & \\
\hline \multicolumn{4}{|l|}{ HBeAg status } \\
\hline Negative & $8 / 186,4.30 \%$ & 1 & \\
\hline Positive & $22 / 465,4.73 \%$ & $1.10(0.46-2.92)$ & \\
\hline \multicolumn{4}{|c|}{ HBV DNA before delivery } \\
\hline$<10^{6}$ copies $/ \mathrm{mL}$ & $14 / 264,5.30 \%$ & 1 & \\
\hline$\geq 10^{6}$ copies $/ \mathrm{mL}$ & $16 / 387,4.13 \%$ & $1.39(1.17-1.64)$ & $1.21(1.02-1.44)$ \\
\hline \multicolumn{4}{|l|}{ ALT at baseline (U/L) } \\
\hline $0-40$ & $10 / 218,4.59 \%$ & 1 & \\
\hline $41-80$ & $9 / 178,5.06 \%$ & $1.11(0.44-2.79)$ & \\
\hline$>80$ & $11 / 255,4.31 \%$ & $0.94(0.39-2.25)$ & \\
\hline \multicolumn{4}{|l|}{ Telbivudine treatment } \\
\hline No & $29 / 400,7.25 \%$ & 1 & \\
\hline Yes & $1 / 251,0.40 \%$ & $0.05(0.01-0.38)$ & $0.07(0.01-0.55)$ \\
\hline \multicolumn{4}{|l|}{ Gestation week } \\
\hline$\geq 37$ weeks & $29 / 620,4.68 \%$ & 1 & \\
\hline$<37$ weeks & $1 / 31,3.23 \%$ & $0.68(0.09-5.16)$ & \\
\hline \multicolumn{4}{|l|}{ Mode of delivery } \\
\hline Vaginal delivery & $22 / 148,14.86 \%$ & 1 & \\
\hline Caesarean section & $8 / 503,1.59 \%$ & $0.09(0.03-0.22)$ & $0.72(0.31-1.69)$ \\
\hline \multicolumn{4}{|l|}{ Fetal distress } \\
\hline No & $27 / 515,5.24 \%$ & 1 & \\
\hline Yes & $3 / 136,2.21 \%$ & $0.41(0.12-1.36)$ & \\
\hline \multicolumn{4}{|c|}{ Postpartum hemorrhage } \\
\hline No & $28 / 614,4.56 \%$ & 1 & \\
\hline Yes & $2 / 37,5.41 \%$ & $1.20(0.27-5.22)$ & \\
\hline \multicolumn{4}{|c|}{ Meconium staining of the amniotic fluid } \\
\hline No & $27 / 521,5.18 \%$ & 1 & \\
\hline Yes & $3 / 130,2.31 \%$ & $0.43(0.13-1.45)$ & \\
\hline \multicolumn{4}{|c|}{ Premature rupture of membrane } \\
\hline No & $28 / 585,4.79 \%$ & 1 & \\
\hline Yes & $2 / 66,3.03 \%$ & $0.62(0.14-2.67)$ & \\
\hline
\end{tabular}

multicenter study from $\mathrm{Hu} \mathrm{Y}$ et al. [29] found that $2.3 \%$ $(3 / 128)$ of the infants in the treatment group had severe adverse events (one case had congenital right ear loss, another one was diagnosed with cerebral palsy at 6 months, and the other one had motor dysplasia (could not stand alone)), while no obvious adverse events were observed in the control group $(P<0.001)$. As a retrospective study, we could not include prenatal adverse events such as spontaneous abortion and stillbirth. However, we did not identify any congenital malformations or mental retardation among the 251 infants born from mothers who were in the LdT-treated group. Yet, studies regarding the long-term safety of antiviral therapy during late pregnancy to block MTCT of HBV still need more data and long-time follow-up in the future.

In conclusion, maternal antiviral treatment with LdT during late pregnancy can effectively reduce the viral load and promote liver function recovery. Moreover, it can also reduce the MTCT rate of $\mathrm{HBV}$.

\section{Data Availability}

The data used to support the findings of this study are available from the corresponding author upon request.

\section{Disclosure}

Mengzhi Cai and Yanli Hao are co-first authors.

\section{Conflicts of Interest}

The authors declare that there are no conflicts of interest regarding the publication of this paper.

\section{Authors' Contributions}

Mengzhi Cai and Yanli Hao reviewed and searched the literature, wrote the protocol, collected the data, performed 
the statistical analysis, interpreted the data, and drafted the manuscript. Jianxin Zhong, Wei Yao, and Xia Cao enrolled the participants and collected the data. Gang Qin conceived the work and performed the statistical analysis and critical revision of the manuscript for important intellectual content. Guifang $\mathrm{Gu}$ wrote the protocol, performed the statistical analysis, and revised the manuscript. All authors have made an intellectual contribution to the manuscript and approved the submission. Mengzhi Cai and Yanli Hao contributed equally to this article.

\section{Acknowledgments}

We would like to thank all the participants from Nantong Third People's Hospital and Affiliated Hospital of Nantong University. This study was supported in part by Grant nos. F201807 and LGY2017039 from Jiangsu Provincial Department of Health, China and by Grant no. BE2015655 from the Jiangsu Provincial Department of Science and Technology, China.

\section{References}

[1] I. Gentile and G. Borgia, "Vertical transmission of hepatitis B virus: challenges and solutions," International Journal of Women's Health, vol. 6, pp. 605-611, 2014.

[2] R. Lozano, M. Naghavi, K. Foreman et al., "Global and regional mortality from 235 causes of death for 20 age groups in 1990 and 2010: a systematic analysis for the Global Burden of Disease Study 2010," The Lancet, vol. 380, no. 9859, pp. 2095-2128, 2012.

[3] Chinese Society of Hepatology CMA, Chinese Society of Infectious Diseases CMA, J.-L. Hou, and W. lai, "The guideline of prevention and treatment for chronic hepatitis B: a 2015 update," Zhong Hua Gan Zang Bing Za Zhi, vol. 23, no. 12, pp. 888-905, 2015.

[4] S. T. Goldstein, F. Zhou, S. C. Hadler, B. P. Bell, E. E. Mast, and H. S. Margolis, "A mathematical model to estimate global hepatitis B disease burden and vaccination impact," International Journal of Epidemiology, vol. 34, no. 6, pp. 1329-1339, 2005.

[5] F.-S. Wang, J.-G. Fan, Z. Zhang, B. Gao, and H.-Y. Wang, "The global burden of liver disease: the major impact of China," Hepatology, vol. 60, no. 6, pp. 2099-2108, 2014.

[6] A. Schweitzer, J. Horn, R. T. Mikolajczyk, G. Krause, and J. J. Ott, "Estimations of worldwide prevalence of chronic hepatitis $B$ virus infection: a systematic review of data published between 1965 and 2013," The Lancet, vol. 386, no. 10003, pp. 1546-1555, 2015.

[7] D. Lavanchy, "Chronic viral hepatitis as a public health issue in the world," Best Practice \& Research Clinical Gastroenterology, vol. 22, no. 6, pp. 991-1008, 2008.

[8] M. M. Jonas, "Hepatitis B and pregnancy: an underestimated issue," Liver International : Official Journal of The International Association for The Study of The Liver, vol. 29, no. 1, pp. 133-139, 2009.

[9] Organization WH, "WHO | Guidelines for the prevention, care and treatment of persons with chronic hepatitis B infection," World Health Organization, 2015.

[10] G. Han, M. Cao, W. Zhao et al., "A prospective and open-label study for the efficacy and safety of telbivudine in pregnancy for the prevention of perinatal transmission of hepatitis B virus infection," Journal of Hepatology, vol. 55, no. 6, pp. 1215-1221, 2011.

[11] E. Sagnelli, T. Stroffolini, A. Mele et al., "Impact of comorbidities on the severity of chronic hepatitis B at presentation," World Journal of Gastroenterology, vol. 18, no. 14, pp. 1616-1621, 2012.

[12] B. J. McMahon, W. L. M. Alward, D. B. Hall et al., "Acute hepatitis $\mathrm{B}$ virus infection: relation of age to the clinical expression of disease and subsequent development of the carrier state," The Journal of Infectious Diseases, vol. 151, no. 4, pp. 599603, 1985.

[13] H. Komatsu, A. Inui, T. Fujisawa et al., "Transmission route and genotype of chronic hepatitis B virus infection in children in Japan between 1976 and 2010: A retrospective, multicenter study," Hepatology Research, vol. 45, no. 6, pp. 629-637, 2015.

[14] Q. Sheng, Y. Ding, B. Li et al., "Efficacy and safety of nucleos $(\mathrm{t})$ ide analogues to prevent hepatitis $\mathrm{B}$ virus motherto-child transmission in pregnant women with high viremia: real life practice from China," International Journal of Medical Sciences, vol. 15, no. 8, pp. 796-801, 2018.

[15] G. Jourdain, N. Ngo-Giang-Huong, L. Harrison et al., "Tenofovir versus Placebo to prevent perinatal transmission of Hepatitis B. The New England journal of medicine," The New England Journal of Medicine, vol. 378, no. 10, pp. 911-923., 2018.

[16] N. A. Terrault, N. H. Bzowej, K.-M. Chang, J. P. Hwang, M. M. Jonas, and M. H. Murad, "AASLD guidelines for treatment of chronic hepatitis B," Hepatology, vol. 63, no. 1, pp. 261-283, 2016.

[17] H. Zou, Y. Chen, Z. Duan, H. Zhang, and C. Pan, "Virologic factors associated with failure to passive-active immunoprophylaxis in infants born to HBsAg-positive mothers," Journal of Viral Hepatitis, vol. 19, no. 2, pp. e18-e25, 2012.

[18] C. Lee, Y. Gong, J. Brok, E. H. Boxall, and C. Gluud, "Effect of hepatitis B immunisation in newborn infants of mothers positive for hepatitis B surface antigen: systematic review and meta-analysis," British Medical Journal, vol. 332, no. 7537, pp. 328-332, 2006.

[19] W. Xu, Y. Cui, L. Wang et al., "Lamivudine in late pregnancy to prevent perinatal transmission of hepatitis B virus infection: a multicentre, randomized, double-blind, placebo-controlled study," Journal of Viral Hepatitis, vol. 16, no. 2, pp. 94-103, 2009.

[20] C. Q. Pan, Z. Duan, E. Dai et al., “Tenofovir to prevent hepatitis B transmission in mothers with high viral load," The New England Journal of Medicine, vol. 374, no. 24, pp. 2324-2334, 2016.

[21] N. A. Terrault, A. S. F. Lok, B. J. McMahon et al., "Update on prevention, diagnosis, and treatment of chronic hepatitis B: AASLD 2018 hepatitis B guidance," Hepatology, vol. 67, no. 4, pp. 1560-1599, 2018.

[22] H. L. Chen, C. N. Lee, C. H. Chang et al., "Efficacy of maternal tenofovir disoproxil fumarate in interrupting mother-to-infant transmission of hepatitis B virus," Hepatology, vol. 62, no. 2, pp. 375-386, 2015.

[23] L. Grønbæk, H. Vilstrup, and P. Jepsen, "Autoimmune hepatitis in Denmark: incidence, prevalence, prognosis, and causes of death. A nationwide registry-based cohort study," Journal of Hepatology, vol. 60, no. 3, pp. 612-617, 2014.

[24] J. Van Schalkwyk, M. Nourmoussavi, A. Massey et al., "Missed opportunities for prevention of perinatal transmission of hepatitis b: A retrospective cohort study," Canadian Journal of Gastroenterology and Hepatology, vol. 28, no. 10, pp. 525-528, 2014.

[25] C. Q. Pan, G.-R. Han, H.-X. Jiang et al., “Telbivudine prevents vertical transmission from HBeAg-Positive women with 
chronic hepatitis B," Clinical Gastroenterology and Hepatology, vol. 10, no. 5, pp. 520-526, 2012.

[26] H. Miyata and S. Miyata, "Speculation of the time-dependent change of FIB4 Index in patients with nonalcoholic fatty liver disease: a retrospective study," Canadian Journal of Gastroenterology and Hepatology, vol. 2018, Article ID 5323061, 11 pages, 2018.

[27] Z. Chen, G. Gu, Z. Bian et al., "Clinical course and perinatal transmission of chronic hepatitis B during pregnancy: A realworld prospective cohort study," Infection, vol. 75, no. 2, pp. 146154, 2017.

[28] Y. Ding, Y. Hu, and L. Yu, “The impact of intrahepatic cholestasis of pregnancy with hepatitis B virus infection on perinatal outcomes," Therapeutics and Clinical Risk Management, vol. 10, pp. 381-385, 2014.

[29] Y. Hu, C. Xu, B. Xu et al., "Safety and efficacy of telbivudine in late pregnancy to prevent mother-to-child transmission of hepatitis B virus: A multicenter prospective cohort study," Journal of Viral Hepatitis, vol. 25, no. 4, pp. 429-437, 2018.

[30] S. Ranger-Rogez, S. Alain, and F. Denis, "Hepatitis viruses: Mother-to-child transmission," Pathologie Biologie, vol. 50, no. 9, pp. 568-575, 2002.

[31] C.-L. Lai, E. Gane, Y.-F. Liaw et al., "Telbivudine versus lamivudine in patients with chronic hepatitis B," The New England Journal of Medicine, vol. 357, no. 25, pp. 2576-2588, 2007.

[32] Y. Bacq, "Hepatitis B and pregnancy," Gastroenterologie Clinique et Biologique, vol. 32, pp. S12-S19, 2008.

[33] M. Wang, Q. Bian, Y. Zhu et al., "Real-world study of tenofovir disoproxil fumarate to prevent hepatitis B transmission in mothers with high viral load," Alimentary pharmacology therapeutics, vol. 49, no. 2, pp. 211-217, 2019.

[34] H. Zhang, C. Q. Pan, Q. Pang, R. Tian, M. Yan, and X. Liu, "Telbivudine or lamivudine use in late pregnancy safely reduces perinatal transmission of hepatitis B virus in real-life practice," Hepatology, vol. 60, no. 2, pp. 468-476, 2014.

[35] W.-H. Wen, M.-H. Chang, L.-L. Zhao et al., "Mother-to-infant transmission of hepatitis B virus infection: significance of maternal viral load and strategies for intervention," Journal of Hepatology, vol. 59, no. 1, pp. 24-30, 2013.

[36] L. Zhang, X. Gui, B. Wang et al., "Serological positive markers of hepatitis B virus in femoral venous blood or umbilical cord blood should not be evidence of in-utero infection among neonates," BMC Infectious Diseases, vol. 16, no. 1, Article ID 408, 2016.

[37] H. Chen, M. Zha, J. Cai, and G. Qin, "Maternal viral load and hepatitis $\mathrm{B}$ virus mother-to-child transmission risk: A systematic review and meta-analysis," Hepatology Research, vol. 48, no. 10, pp. 788-801, 2018.

[38] U. Navaneethan, M. Al Mohajer, and M. T. Shata, "Hepatitis E and pregnancy: understanding the pathogenesis," Liver International, vol. 28, no. 9, pp. 1190-1199, 2008.

[39] Y. Yin, L. Wu, J. Zhang, J. Zhou, P. Zhang, and H. Hou, "Identification of risk factors associated with immunoprophylaxis failure to prevent the vertical transmission of hepatitis B virus," Infection, vol. 66, no. 5, pp. 447-452, 2013.

[40] K. Sun, J. Li, F. Zhu et al., "A predictive value of quantitative HBsAg for serum HBV DNA level among HBeAg-positive pregnant women," Vaccine, vol. 30, no. 36, pp. 5335-5340, 2012.

[41] H. L. Chen, L. H. Lin, F. C. Hu et al., "Effects of maternal screening and universal immunization to prevent mother-toinfant transmission of HBV,' Gastroenterology, vol. 142, no. 4, pp. 773-781, 2012.
[42] G. Han, H. Jiang, C. Wang et al., "Long-term safety and efficacy of telbivudine in infants born to mothers treated during the second or third trimesters of pregnancy," Journal of Viral Hepatitis, vol. 24, no. 6, pp. 514-521, 2017. 


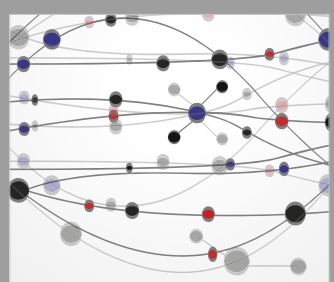

The Scientific World Journal
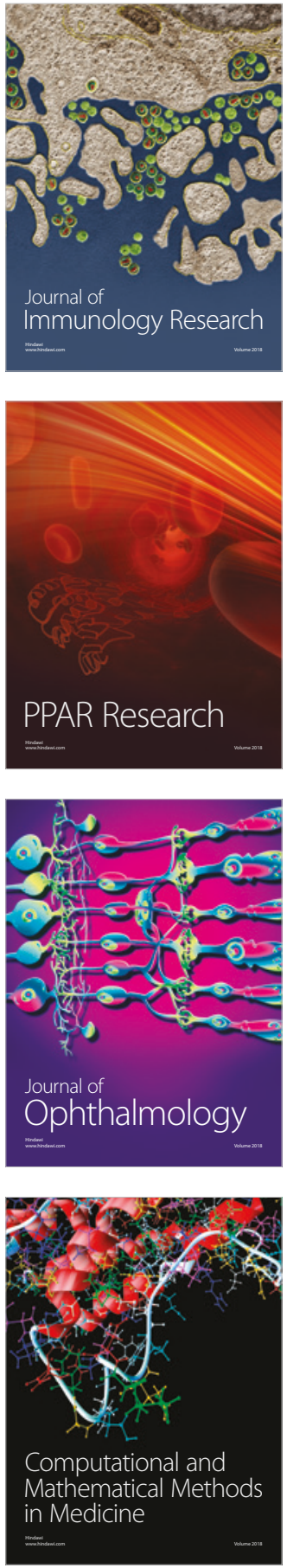

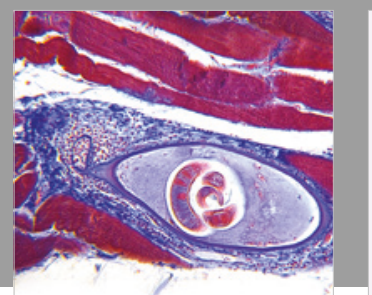

Gastroenterology Research and Practice

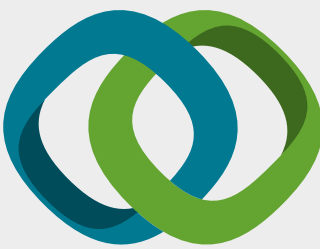

\section{Hindawi}

Submit your manuscripts at

www.hindawi.com
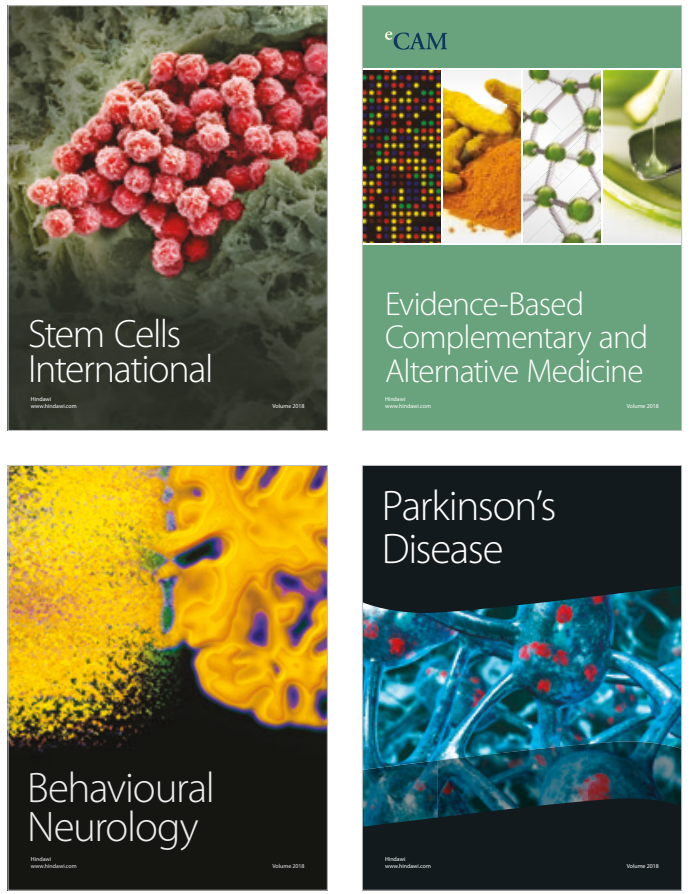

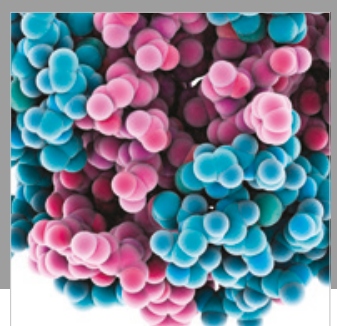

ournal of

Diabetes Research

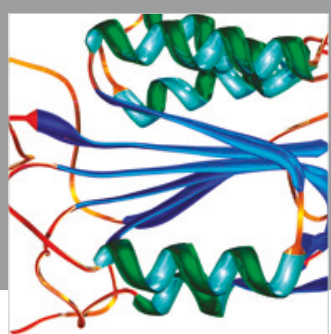

Disease Markers
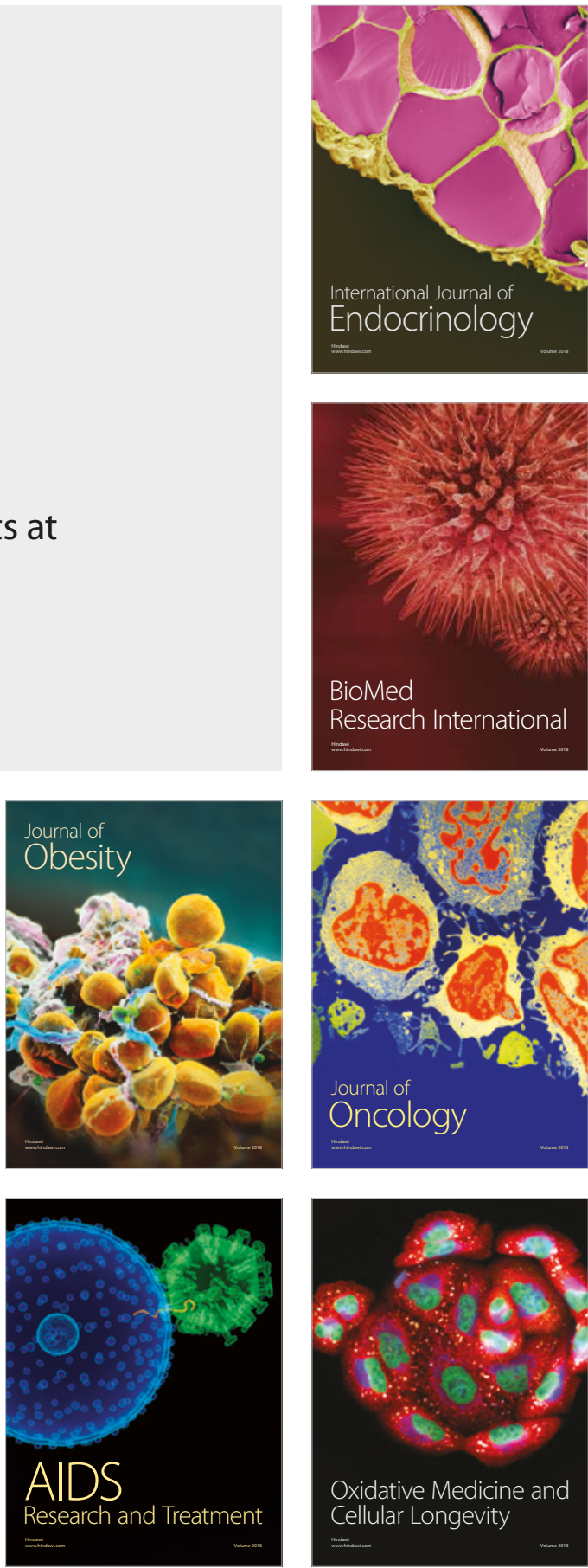